EDITORIAL

\title{
Health Equity or Iniquity?
}

\author{
Kenneth R. McLeroy • Monica L. Wendel
}

Published online: 13 February 2011

(C) Springer Science+Business Media, LLC 2011

We want to thank our colleagues Michael Dubois and David Buchanan for raising important issues in the ethics and economics of prevention that provide the foundation for this editorial. In Dubois's article, he highlights some of the philosophical arguments surrounding the inclusion of prevention policies in private and publicly-funded health insurance. In particular, he recounts the argument that individuals have an obligation to make a productive contribution to society and the importance of social solidarity—an argument that may be more prominent in European discourse than in the US. In response, Buchanan utilizes the example of German health insurance to illustrate the tension between the social good and solidarity, pointing out that an individual taking active steps to be healthy may be viewed as contributing to the common good but that prevention policies may also undermine solidarity by disproportionately rewarding those who are already advantaged.

Several arguments in these articles and in the public discourse related to health and health care

K. R. McLeroy ( $\bowtie)$

Department of Health Promotion and Community

Sciences, Texas A\&M School of Rural Public Health,

College Station, TX, USA

e-mail: KMcLeroy@srph.tamhsc.edu

M. L. Wendel

Center for Community Health Development, Texas A\&M

School of Rural Public Health, College Station, TX, USA

e-mail: mlwendel@srph.tamhsc.edu focus on individual responsibility; however, it is frequently unclear what individual responsibility really means and how that may affect health and other outcomes (Wikler 1987). For example, some argue that individual lifestyle choices and behavior are linked to certain diseases and health outcomes, but the magnitude of that link is questionable for many behaviors of interest in the practice of prevention. Moreover, even when there is a strong link between a behavior and a health outcome, some behaviors are not entirely under the control of the individual, and even those under individual control may be strongly influenced by social and structural factors (Krieger 2008). As Buchanan argues, context may restrict the choices and behaviors under individual control.

Dan Wikler (1987) also raised a key question about the ideological underpinnings of assuming that individuals are solely (or even primarily) responsible for their health. He concluded, "The debate over personal responsibility for health...is also about the degree of responsibility for the health of the public which ought to be placed on non-persons, primarily industry and government. The argument for assigning responsibility for health to the individual is often an attempt to absolve these larger institutions of blame for having caused sickness or for having failed to provide care, respectively" (p. 24). Presumably, if individuals are responsible for their health, then society may have little obligation to assure health services and the conditions under which individuals 
have the opportunity to be healthy. But, social solidarity is about more than the rights of individuals to health care. As noted by Callahan and Wasunna (2006), many if not most of the European countries do not view health care as an individual right; rather, health care is viewed as something that we owe each other as members of the same country. It is about solidarity, shared culture, and mutual responsibility.

This is more than a philosophical argument. It represents a basic social and economic issue about who benefits and who pays for individuals' behaviors and their role in the demand for health care. As a society, do we want to hold individuals responsible for their behavior when as a society, we have created systematic disadvantage for certain groups? What should individuals be responsible to do? And collectively, what should we as a society be responsible to do? What are the obligations and duties between individuals and the broader society and social system? Though some argue vehemently one side or the other-either the individual has a responsibility to act in socially acceptable ways or the society has the responsibility to reduce the risk to individuals - the reality lies somewhere in between. Certainly, one obligation of society is to provide opportunities for equity, if not equity itself. As noted by Amartya Sen, this issue of "health equity cannot but be a central feature of the justice of social arrangements in general $\cdots$. It must come to groups with the larger issue of fairness and justice in social arrangements, including economic allocations, paying appropriate attention to the role of health in human life and freedom" (Anand et al. 2004, p. 21). In short, inequity in health and health care are symptoms of social arrangements that produce inequity in general.

Sandel (2009) makes a poignant statement that underlines the ongoing debate regarding health as a right or privilege in the US:
After all, people in pluralist societies such as ours disagree about the best way to live.... Many of the most hotly contested issues of justice and rights can't be debated without taking up controversial moral and religious questions. In deciding how to define the rights and duties of citizens, it's not always possible to set aside competing conceptions of the good life. And even when it's possible, it may not be desirable. (p. 243)

As the debate continues regarding society's obligation to its members and individuals' obligation to each other and society, we encourage you to focus on both the individual and social determinants of health, issues of justice and fairness, and issues of solidarity.

Acknowledgments This article was made possible, in part, by cooperative agreement number 1U48DP001924 from the Centers for Disease Control and Prevention (CDC), and by grant number P20MD002295 from the National Institute for Minority Health and Health Disparities. The views expressed in this publications are those of the authors and do not necessarily reflect the official views or policies of the CDC or the Department of Health and Human Services.

\section{References}

Anand, S., Peter, F., \& Sen, A. (Eds.). (2004). Public health, ethics, and equity. New York, NY: Oxford University Press.

Callahan, D., \& Wasunna, A. A. (2006). Medicine and the market: Equity v. choice. Baltimore, MD: The Johns Hopkins University Press.

Krieger, N. (2008). Proximal, distal, and the politics of inequality: What's level got to do with it? American Journal of Public Health, 98(2), 221-230.

Sandel, M. J. (2009). Justice: What's the right thing to do?. New York, NY: Farrar, Straus and Giroux.

Wikler, D. (1987). Who should be blamed for being sick? Health Education and Behavior, 14(1), 11-25. 